\section{OPEN ACCESS}

Edited by:

Gabriele Giorgi,

European University of Rome, Italy

Reviewed by:

Leonidas A. Zampetakis,

Technical University of Crete, Greece

Krystyna Golonka

Jagiellonian University, Poland

*Correspondence:

Reuven Bar-On

reuven@reuvenbaron.org

Specialty section

This article was submitted to

Organizational Psychology,

a section of the journal

Frontiers in Psychology

Received: 17 July 2017

Accepted: 29 January 2018

Published: 21 February 2018

Citation:

Bar-On R (2018) The Multifactor

Measure of Performance: Its

Development, Norming, and Validation. Front. Psychol. 9:140.

doi: 10.3389/fpsyg.2018.00140

\title{
The Multifactor Measure of Performance: Its Development, Norming, and Validation
}

\section{Reuven Bar-On*}

The National Institute for the Regulation of Emergencies and Disasters (NIRED), College of Law and Business, Ramat Gan, Israel

This article describes the development as well as the initial norming and validation of the Multifactor Measure of Performance ${ }^{\mathrm{TM}}\left(\mathrm{MMP}^{\mathrm{TM}}\right)^{1}$, which is a psychometric instrument that is designed to study, assess and enhance key predictors of human performance to help individuals perform at a higher level. It was created by the author, for the purpose of going beyond existing conceptual and psychometric models that often focus on relatively few factors that are purported to assess performance at school, in the workplace and elsewhere. The relative sparsity of multifactorial pre-employment assessment instruments exemplifies, for the author, one of the important reasons for developing the $\mathrm{MMP}^{\mathrm{TM}}$, which attempts to comprehensively evaluate a wider array of factors that are thought to contribute to performance. In that this situation creates a need in the area of test-construction that should be addressed, the author sought to develop a multifactorial assessment and development instrument that could concomitantly evaluate a combination of physical, cognitive, intra-personal, inter-personal, and motivational factors that significantly contribute to performance. The specific aim of this article is to show why, how and if this could be done as well as to present and discuss the potential importance of the results obtained to date. The findings presented here will hopefully add to what is known about human performance and thus contribute to the professional literature, in addition to contribute to the continued development of the $M_{M}{ }^{T M}$. The impetus for developing the MMPTM is first explained below, followed by a detailed description of the process involved and the findings obtained; and their potential application is then discussed as well as the possible limitations of the present research and the need for future studies to address them.

Keywords: multifactor measure of performance, MMP3, Reuven Bar-On, performance, assessing and developing performance

\section{INTRODUCTION}

While the beta version of Multifactor Measure of Performance ${ }^{\mathrm{TM}}$ (referred to as the "MMP1"TM"), the key predictors of performance it was designed to measure and the initial research involved in developing it were first described by the author in an earlier publication (Bar-On, 2016), the purpose of the present article is to describe the latest version and third revision of the

\footnotetext{
${ }^{1}$ The $\mathrm{MMP}^{\mathrm{TM}}$ is the intellectual property (IP) of Bar-On Test Developers.
} 
$\mathrm{MMP}^{\mathrm{TM}}$ - "MMP3 ${ }^{\mathrm{TM}}$ " - and how it was created, normed and validated based on research that was conducted since that first publication. This article documents the continuation of the original research that was conducted by the author and first reported in 2016 (Bar-On, 2016) and presents the basic psychometric properties, strengths, and potential applicability of the MMP3 ${ }^{\mathrm{TM}}$.

The primary purpose and focus of this introductory section is to explain the basic reasons for conducting the initial research that led to the creation of the Multifactor Measure of Performance $^{\mathrm{TM}}$ and the specific context in which this work began. One of the author's reasons for beginning this research emerged from reviewing, over the years, a wide variety instruments that were designed to assess various aspects of human behavior and performance. This review indicated, early on, a need for multifactor assessment instruments capable of concomitantly evaluating a combination of predictors of performance, which would hopefully reduce the need for time-consuming and costly batteries of tests in psycho-assessment. Additionally, this need to develop a multifactor assessment instrument, designed to measure human performance, emerged from the desire to, metaphorically, "go beyond IQ and EQ" (Bar-On, 2016, p. 104) and include a wide array of physical, cognitive, intrapersonal, inter-personal, and motivational contributors to and predictors of performance. Furthermore, the author's overall approach to this endeavor was purposely a-theoretical in nature from the outset, in order to avoid being restrained by rigid conceptual frameworks that run the risk of restricting rather than facilitating the ability to examine and potentially include a wider range of contributors to human performance. Essentially, the author envisioned the development of a multifactor assessment instrument that endeavors to include as many significant contributors to performance as possible and to combine them to enhance overall predictive ability.

The above-mentioned need for a better assessment instrument was once again confirmed by a survey that the author recently conducted of existing pre-employment tests. Based on a random sample of 120 of the 359 pre-employment tests listed in the 20th edition of the Mental Measurement Yearbook (MMY), he found that there appears to be eight major categories describing the vast majority of presently available tests (Carlson et al., 2017). These eight categories are listed in Appendix A and include the number of pre-employment tests identified in each category based on a random sampling of every third test listed in the latest edition of the MMY. A review of Appendix A indicates the percentage of pre-employment tests that are designed to obtain the following information from individuals exploring careers and from job applicants: (1) $9 \%$ identify vocational and career interests; (2) 20\% evaluate employability as well as general and specific employment skills; (3) $37 \%$ examine cognitive or academic potential; (4) $14 \%$ assess intrapersonal competencies and personality traits; (5) 5\% estimate inter-personal compatibility and communication skills; (6) $3 \%$ tap managerial and leadership skills; (7) $8 \%$ focus on job commitment, social responsibility, work ethics, honesty and/or dependability; and (8) $3 \%$ attempt to screen for possible disruptive psychological problems and/or potential criminal behavior. It is interesting to note that almost none of the preemployment tests reviewed evaluate motivational drive, which is thought to be an important predictor of performance in the workplace and elsewhere (Weitz et al., 1986; Cotton, 1993; Becker et al., 1996; Diefendorff et al., 2002; Locke and Latham, 2002; Halbesleben and Wheeler, 2008; Markos and Sridevi, 2010; Rich et al., 2010). While the MMP3 $3^{\mathrm{TM}}$ was not designed to identify vocational interests or specific occupational skills, it will be shown in the Results section that it is capable of assessing most of the factors that many of the pre-employment tests are designed to evaluate as well as additional factors that they do not assess. The author's examination of the pre-employment tests reviewed by MMY also suggests that they focus on an average of five potential predictors of performance, while the MMP3 ${ }^{\mathrm{TM}}$ focuses on 25 contributors to performance in the workplace and elsewhere. The MMP3 ${ }^{\mathrm{TM}}$, moreover, combines multifactor contributors to performance in one assessment instrument including (1) physical, (2) cognitive, (3) intra-personal, (4) interpersonal, and (5) motivational factors; and this has the potential of significantly reducing the need to create a battery of preemployment tests to obtain a more comprehensive evaluation of job applicants, which can be obtained from one assessment instrument (i.e., the MMP3 ${ }^{\mathrm{TM}}$ ). Last, the predictive validity of many pre-employment tests listed is not always available in the MMY nor is it frequently convincing when findings are documented in the peer-reviewed literature.

The main reason for developing the Multifactor Measure of Performance $^{\mathrm{TM}}$ can be summarized as the need to develop a better assessment instrument than currently exists. Moreover, the ultimate aim of creating such an instrument is to substantially contribute to the study, assessment and enhancement of human performance; and the primary purpose of this article is to describe the process involved, which is explained in detail below, as well as to present the key findings, discuss their importance and potential application.

\section{METHODOLOGY}

\section{Sample}

The approach used to obtain subjects, in the present study, was to make the 189-item MMP2 ${ }^{\mathrm{TM}}$ available on SurveyMonkey.com and circulate the link to a number of websites, organizations, and individuals in United States and Canada. This same approach was also used in piloting the beta version of this questionnaire (the $\mathrm{MMP} 1^{\mathrm{TM}}$ ). In that the initial piloting and norming of this instrument was done on the Internet and not in an academic, medical, or government setting, formal permission was not requested from an official institutional review board to conduct this research. It is also important to convey that the participants were not paid to participate in this research project nor were they coerced to do so in any manner whatsoever. Additionally, it was clearly stated in the introductory section of the $\mathrm{MMP}^{\mathrm{TM}}$ that completing the questionnaire was solely for research purposes. In very similar formats moreover, it was also stated at the beginning and at the end of the introductory section that "your agreement to participate in this project, by completing the questionnaire, means that you have given your voluntary consent to do so." 
The above-mentioned process of making the questionnaire available on the Internet generated a sample of, primarily, North American subjects that included a total of 2,380 adults with an average age of 38.0 years. Those who identified their gender and age $(n=2,004)$ included 1,064 males with an average age of 38.4 years and 940 females with an average age of 37.4 years. As is the case with voluntary participation in research, it is difficult to determine the degree to which this population sample represents the total population (although this can be statistically estimated by examining the standard error of the means for the scale scores as is explained in the Results section of this article).

\section{Data Collection}

The MMP2 $2^{\mathrm{TM}}$ was the main source of data collection used in the present study to develop of the third and most recent version of the questionnaire-the MMP3 $3^{\mathrm{TM}}$-described in the present article. In an effort to briefly clarify the differences between these three versions of the Multifactor Measure of Performance ${ }^{\mathrm{TM}}$,

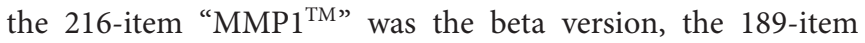
"MMP2 $2^{\mathrm{TM}}$ " is the second version, and the 142 -item "MMP3 3 "M" is the third and most recent version. While the development of the MMP1 $1^{\mathrm{TM}}$ was described in an earlier publication in greater detail (Bar-On, 2016), the development the $\mathrm{MMP}^{\mathrm{TM}}$ and $\mathrm{MMP}^{\mathrm{TM}}$ is described in this article.

The author's approach in developing the original $\mathrm{MMP}^{\mathrm{TM}}$ was based on the test-construction strategy he applied in developing other psychometric instruments he has developed over the years (Bar-On, 1988, 1997, 2000, 2004, 2006). This involved the following steps: (1) first identifying factors in the literature thought to contribute to performance; (2) receiving input from experienced professionals- "experts"-who have researched, assessed and/or developed performance; (3) then selecting and defining the contributors to and predictors of performance that emerged from his review of the literature and input he received from others; and (4) finally creating, selecting, and further editing scale items. This process created the MMP1 ${ }^{\mathrm{TM}}$, the beta version of the questionnaire, which comprised 26 primary scales and two validity scales containing a total of 216 items. The two validity scales are unrelated to performance but were included to help examine response accuracy ("SelfImage Accuracy") and consistency ("Self-Image Consistency"). The Self-Image Accuracy scale originally contained eight items in the MMP1 $1^{\mathrm{TM}}$, while the Self-Image Consistency scale was created by averaging the absolute differences in responses to the instrument's highest correlating items across scales. The 26 major scales that were designed to assess contributors to performance, that the author originally identified, and used to develop the $M M P 1^{\mathrm{TM}}$, are listed in Appendix B. While a detailed description of how the MMP1 ${ }^{\mathrm{TM}}$ scales were identified, labeled, and defined as well as how the items were selected appear in an earlier publication (Bar-On, 2016), those scales that were retained and included in the MMP3 ${ }^{\mathrm{TM}}$ are described in the Results section of this article. The response format originally considered was a 5point Likert scale; however, it was eventually decided to use a slider bar to report responses in percentages based on the author's desire to go from an ordinal to a more statistically sophisticated ratio level of measurement with equal intervals that also include a true zero value (i.e., $0-100 \%$ ). The $\mathrm{MMP}^{\mathrm{TM}}$ was piloted on 997 adults in 2015. The eight items in each scale were then examined with Item Analysis, in order to identify the psychometrically weakest items (i.e., those with the lowest item-scale correlation). This was done to (a) shorten and (b) psychometrically strengthen the questionnaire, by deleting the weakest item and retaining the strongest ones in each scale. This process created the 189item MMP2 $2^{\mathrm{TM}}$, with 27 scales (including one of the validity scales previously mentioned) comprising seven items in each scale.

An additional source of data collection was the application of a method designed to estimate current occupational performance for those who completed the MMP2 $2^{\mathrm{TM}}$, based on including the following question toward the end of the questionnaire: "If your organization would use the following format to evaluate your work, please indicate how your overall performance was most recently rated on a scale of $0-100 \%$." The responses from (a) those who answered this question and (b) who also responded with a score of $65 \%$ or greater to the following question were used to examine the questionnaire's validity: "Please indicate how often you responded openly and accurately to this questionnaire on a scale of $0-100 \%$ of the time." This generated a sample of 1,788 individuals that was used in examining the questionnaire's discriminatory and predictive validity, which is explained in the data analysis sub-section below.

\section{Data Analysis}

In light of the fact that the data collection procedure employed was multivariate in nature, multivariate statistics were applied to examine responses generated by the 189 -item $\mathrm{MMP} 2^{\mathrm{TM}}$ and the 142 -item MMP3 ${ }^{\mathrm{TM}}$; and the specific statistical applications applied are described below. The statistical package used by the author was "Statistica $12.7^{2}$."

\section{Exploratory Factor Analysis (EFA)}

EFA was used to estimate the factorial structure of the MMP2 ${ }^{\mathrm{TM}}$, which guided the development of the $\mathrm{MMP}^{\mathrm{TM}}$. The EFA was conducted on the responses generated by the $\mathrm{MMP}^{\mathrm{TM}}$ $(n=2,380)$. Nine consecutive EFAs were carried out, in which factor output was limited by progressing from 18 to 26 factors. This was done to estimate the simplest and clearest factorial structure using a varimax normalized rotation. In that the statistical package used did not include oblique rotations, the application of orthogonal rotations needed to be justified and was based on a number of well-documented arguments in the literature since Spearman (1950) and Cattell (1952) first introduced the use of factor analysis in psychology. It has been consistently emphasized that the fundamental goal of EFA is to obtain a simple factorial structure that is easy to understand (Cattell, 1978; Yaremko et al., 1986; Bryant and Yarnold, 1995; Kline, 2002; Hill and Lewicki, 2006) and makes good theoretical sense (Kim and Mueller, 1978; Vogt, 1993) irrespective if it was obtained by applying an orthogonal or oblique rotation (Kim and Mueller, 1978; Gorsuch, 1983; Brown, 2009). Moreover, Brown (2009, p. 21) concludes from his review of the literature on EFA

\footnotetext{
${ }^{2}$ Statistica 12.7 is referenced in https://en.wikipedia.org/wiki/Statistica.
} 
that "the choice of rotation may not make much difference." Kim and Mueller (1978, p. 50) provide one of the most compelling arguments for applying any rotation that generates a simple structure: "Even the issue of whether factors are correlated or not may not make much difference in the exploratory stages of analysis," and "it even can be argued that employing a method of orthogonal rotation (or maintaining the arbitrary imposition that the factors remain orthogonal) may be preferred over oblique rotation, if for no other reason than that the former is much simpler to understand and interpret." Hill and Lewicki (2006, p. 238) also focus on this particular issue with oblique rotations that the results obtained are "often not easily interpreted." Their conclusion stresses the following important point: "If identification of the basic structuring of variables into theoretically meaningful sub-dimensions is the primary concern of the researcher, as is often the case in an exploratory factor analysis, almost any readily available method of rotation will do the job." Gorsuch (1983, p. 205) also supports this notion and goes one step further: "If the simple structure is clear, any of the more popular procedures can be expected to lead to the same interpretations." In addition to what many of these and other researchers have found, this important point about rotation selection was empirically demonstrated by Brown (2009, p. 23) who received the identical factorial structure and with very similar factor loadings, by examining the same dataset with three orthogonal rotations and two oblique rotations.

\section{Basic Psychometric Properties and Reliability}

Based on the results of EFA, that guided the continued development of the Multifactor Measure of Performance ${ }^{\mathrm{TM}}$, the basic psychometric properties of the MMP3 ${ }^{\mathrm{TM}}$ were examined and are presented in the Results section together with a description of the questionnaire's reliability. This was also conducted on the responses to the questionnaire generated by the North American normative sample $(n=2,380)$.

\section{Analysis of Variance (ANOVA)}

ANOVA was applied to evaluate $\mathrm{MMP}^{\mathrm{TM}}$ 's discriminatory validity, by examining the differences between high and low performers. "High performers" were those who scored +1 SD above the mean on self-reported performance $(n=304)$, as described in the Methodology section, while "low performers" were those who scored -1 SD below the mean $(n=292)$ for this estimate of performance. ANOVA was conducted on the responses to the questionnaire generated by those individuals, in the normative sample, who provided a self-reported estimate of their current occupational performance as well as a score $65 \%$ or higher on accurate and honest responding as was previously described.

\section{Multiple Regression Analysis (MRA)}

MRA was used to examine MMP3 ${ }^{\mathrm{TM}}$ 's predictive validity. The MRA was also conducted on the responses to the questionnaire generated by those individuals who provided a self-reported estimate of their current occupational performance as well as scored $65 \%$ or higher on accurate and honest responding $(n=1,788)$. A forward stepwise analysis was applied.

\section{RESULTS}

\section{MMP3 $^{\text {TM's Factorial Structure }}$}

The simplest and most logical factorial structure of the MMP3 ${ }^{\mathrm{TM}}$ emerged from limiting factor output to 22 factors, based on conducting nine consecutive EFAs in examining the MMP2 ${ }^{\mathrm{TM}}$ 's responses obtained from 2,380 adults who completed the questionnaire. The results are displayed in Tables 1A-C.

In addition to being logical and relatively uncomplicated to interpret, the results appearing in Tables 1A-C suggest that the estimated factorial structure of the MMP3 ${ }^{\mathrm{TM}}$ accounts for nearly $82 \%$ of the total variance that it was designed to capture. Additionally, by comparing the original MMP1 $1^{\mathrm{TM}}$ scales with those that were retained in the $\mathrm{MMP}^{\mathrm{TM}}$, as shown in Appendix B, $\sim 85 \%$ of them were retained. The results indicate that 14 factors and 11 sub-factors ${ }^{3}$ emerged from EFA, with two or more of them loading on factors 3, 15, and 20. In accordance with requiring most of the highest loading items from the original scales being examined load on the resultant output factors that emerge, as suggested by Cattell $(1952,1978)$, Anastasi (1988), Tabachnick and Fidell (2001), a minimum of 4 out of the original $7 \mathrm{MMP}^{\mathrm{TM}}$ scale items was used in identifying the factors in Tables 1A-C. This approach guided the development of the MMP3 ${ }^{\mathrm{TM}}$ with its 14 scales and 11 subscales $^{4}$ that were labeled according to the names of the original $\mathrm{MMP}^{\mathrm{TM}} / \mathrm{MMP}^{\mathrm{TM}}$ scales as well as the specific nature of the highest loading items. As a result of this approach, the labels of a few of the original MMP1 ${ }^{\mathrm{TM}}$ scales were mildly altered. The $\mathrm{MMP}^{\mathrm{TM}}$ scales currently comprise a minimum of 7 items, while the sub-scales contain a minimum of 5 items; and here it is important to mention that 5 items per scale is justified if there is an inner-correlation between them that is equal to or greater than 0.70 (Drolet and Morrison, 2001; Worthigton and Whittaker, 2006; Bergkvist and Rossiters, 2007; Hair et al., 2011), which was confirmed by the results in Table 3.

The results in Table 1A suggest that an additional sub-factor has apparently emerged from EFA, which was not previously considered or described by the author. The highest loading items on this new sub-factor originated from $M M P 1^{\mathrm{TM}}$ 's (a) General Cognitive Competence, (b) Action-Planning, (c) Rapid Implementation, and (d) Discomfort Tolerance scales. An examination of the highest loading items, moreover, suggests that this new sub-factor appears to be associated with being prepared and ready to cope with situations requiring rapid execution of some immediate form of goal-oriented action. It was, therefore, decided to add "Preparedness and Readiness" as an additional $\mathrm{MMP}^{\mathrm{TM}}$ sub-scale designed to assess this particular sub-factor.

\footnotetext{
3"Sub-factors" describe multiple smaller factors, two to six in the present study, that load on the same factor, as are observed in factors 3, 15, and 20 in Tables 1A,C. This term is descriptive in nature rather than statistical.

4 "Sub-scales" describe smaller scales clustered within larger ones. In the MMP3 ${ }^{\mathrm{TM}}$, they appear in the following scales: Key Cognitive Competencies, Finding Meaning and Acting Responsibly, and Motivational Drive. Once again, it is important to note that this term is descriptive rather than statistical.
} 
TABLE 1 | The scale items' highest loadings on the clearest defined factors and sub-factors that emerged from EFA ( $n=2,380)$, appearing in parenthesis following the number of each of these items as listed in the $\mathrm{MMP}^{\mathrm{T} M}{ }_{2}$.

\begin{tabular}{|c|c|c|c|c|}
\hline \multicolumn{5}{|l|}{ A } \\
\hline F1 & F2 & F3 & F4 & F6 \\
\hline Engagement & General Cognitive Competence & Coping and Endurance & Connectedness & Self-Reliance \\
\hline 19. (0.59) & 3. (0.53) & 44. (0.56) & 24. (0.53) & 14. $(0.54)$ \\
\hline 46. $(0.67)$ & 30. $(0.62)$ & 71. (0.54) & 78. $(0.57)$ & 41. $(0.72)$ \\
\hline 73. (0.49) & 57. (0.57) & 98. (0.58) & 105. (0.61) & 68. $(0.76)$ \\
\hline 127. (0.66) & 111. (0.45) & 152. (0.64) & 159. (0.59) & 149. (0.51) \\
\hline 154. (0.59) & & Situational Awareness & 186. (0.37) & \\
\hline \multirow[t]{17}{*}{ 181. (0.62) } & & 4. (0.33) & & \\
\hline & & 58. $(0.40)$ & & \\
\hline & & 139. $(0.47)$ & & \\
\hline & & 166. (0.43) & & \\
\hline & & 114. (0.58) & & \\
\hline & & 141. (0.43) & & \\
\hline & & 168. (0.37) & & \\
\hline & & Resourcefulness and Resilience & & \\
\hline & & 61. (0.51) & & \\
\hline & & 88. $(0.56)$ & & \\
\hline & & 115. (0.52) & & \\
\hline & & 142. (0.58) & & \\
\hline & & Decision-Making & & \\
\hline & & 62. (0.58) & & \\
\hline & & 89. $(0.51)$ & & \\
\hline & & 144. (0.52) & & \\
\hline & & 171. (0.58) & & \\
\hline Var. $=7.04 \%$ & Var. $=5.82 \%$ & Var. $=20.75 \%$ & Var. $=5.48 \%$ & Var. $=3.08 \%$ \\
\hline
\end{tabular}

\begin{tabular}{lccc}
\hline B & F8 & F9 & F11 \\
\hline $\begin{array}{l}\text { Physical Fitness and } \\
\text { Well-Being }\end{array}$ & Courage & $\begin{array}{c}\text { Discomfort Tolerance and } \\
\text { Stamina }\end{array}$ & Decisiveness \\
\hline 1. $(0.71)$ & 15. $(0.63)$ & 83. (0.65) & 13. (0.49) \\
28. $(0.83)$ & 42. $(0.69)$ & 110. $(0.64)$ & 40. $(0.60)$ \\
54. $(0.81)$ & 69. $(0.53)$ & 137. $(0.76)$ & 164. $(0.60)$ \\
55. $(0.56)$ & $96 .(0.54)$ & & $94 .(0.50)$ \\
81. $(0.71)$ & 177. $(0.42)$ & & $175 .(0.41)$ \\
109. $(0.46)$ & & & Var. $=3.31 \%$ \\
163. $(0.38)$ & & Var. $=2.72 \%$ & \\
Var. $=6.37 \%$ & Var. $=3.40 \%$ & & \\
\hline
\end{tabular}


TABLE 1 | Continued

\begin{tabular}{|c|c|c|c|c|}
\hline \multicolumn{5}{|l|}{ C } \\
\hline F12 & F14 & F15 & F19 & F20 \\
\hline Applying Experience & Social Awareness & Self-Motivation & Self-Control & Meaningfulness \\
\hline 5. $(0.48)$ & 23. (0.62) & 18. $(0.46)$ & 16. (0.61) & 26. (0.51) \\
\hline 32. $(0.50)$ & 50. $(0.74)$ & 45. (0.28) & 43. (0.53) & 80. $(0.55)$ \\
\hline 59. (0.49) & 77. (0.77) & 72. (0.53) & 70. (0.55) & 107. (0.40) \\
\hline 86. (0.65) & 104. (0.47) & 99. (0.30) & 97. (0.54) & 134. $(0.47)$ \\
\hline 113. $(0.70)$ & & Determination & 124. (0.53) & 161. (0.36) \\
\hline 140. (0.59) & & 20. $(0.50)$ & 178. (0.44) & Social Responsibility \\
\hline \multirow[t]{11}{*}{ 167. $(0.57)$} & & 47. (0.68) & & 25. (0.38) \\
\hline & & 74. (0.48) & & 52. (0.31) \\
\hline & & 128. (0.56) & & 79. (0.43) \\
\hline & & 155. (0.68) & & 133. (0.27) \\
\hline & & 182. (0.53) & & \\
\hline & & Perseverance & & \\
\hline & & 21. (0.48) & & \\
\hline & & 48. (0.56) & & \\
\hline & & 75. $(0.70)$ & & \\
\hline & & 102. (0.44) & & \\
\hline & & 156. (0.50) & & \\
\hline Var. $=4.60 \%$ & Var. $=3.76 \%$ & Var. $=8.10 \%$ & Var. $=4.07 \%$ & Var. $=3.27 \%$ \\
\hline
\end{tabular}

A further examination of the factor loadings in Tables 1A-C reveals an average factor loading of 0.55 , which could suggest the potential for significant factorial validity; however, this will need to be confirmed by Confirmatory Factor Analysis (CFA) in future studies that will need to be conducted on larger and more diverse independent samples. Additionally, only four out of the 113 highest loadings are lower than 0.32 with the lowest being 0.27 . While 0.30 has been considered the minimum loading for inclusion in resultant factors (Tabachnick and Fidell, 2001), some consider loadings even lower than 0.30 to be acceptable for samples larger than 100 (Kline, 2002, p. 5253).

The MMP3 ${ }^{\mathrm{TM}}$ presently contains 142 items loading on 14 scales and 11 sub-scales, which takes an average of $25 \mathrm{~min}$ to complete based on a North American sample of 468 adults who recently completed this version of the questionnaire.

When the order of the resultant factors in Tables 1A-C are rearranged in a theoretically logical order, the following would appear to be the structure of the factors and sub-factors that are assessed with the MMP3 ${ }^{\mathrm{TM}}$ scales and sub-scales (which will need to be confirmed by CFA to verify this apparent structure):

1. Physical Fitness and Well-Being

2. Discomfort Tolerance and Stamina

3. General Cognitive Competence

4. Key Cognitive Competencies

4.1 Coping and Endurance

4.2 Situational Awareness

4.3 Flexibility

4.4 Resourcefulness and Resilience
4.5 Decision-Making

4.6 Preparedness and Readiness

5. Applying Experience

6. Self-Control

7. Self-Reliance

8. Decisiveness

9. Courage

10. Social Awareness

11. Connectedness

12. Finding Meaning and Acting Responsibly

12.1 Meaningfulness

12.2 Social Responsibility

13. Engagement

14. Motivational Drive

14.1 Self-Motivation

14.2 Determination

14.3 Perseverance

According to how the above factors were originally defined by the author (Bar-On, 2016) and based on the $\mathrm{MMP}^{\mathrm{TM}}$ items that loaded the highest on the factors and sub-factors that emerged from EFA listed in Tables 1A-C, the MMP3 ${ }^{\mathrm{TM}}$ scales and sub-scales are thought to assess the following contributors to performance:

- Physical Fitness and Well-Being: In addition to "striving to obtain and maintain good physical fitness" (Bar-On, 2016, p. 104) which contributes to "overall well-being" (Bar-On, 2016, p. 106), this scale emerged from EFA as a combination of 
two MMP2 $2^{\mathrm{TM}}$ scales which impacts performance. It appears to assess how people feel in general about their physical fitness, eating, and sleeping habits as well as how energetic they typically are in what they do.

- Discomfort Tolerance and Stamina: In addition to the ability to "temporarily suspend everyday physical needs and comforts in order to complete a task" (Bar-On, 2016, p. 104), this scale assesses the willingness to eat at irregular times, work longer hours with less sleep as well as to work on weekends in order to meet deadlines and finish the work on time. It also appears to measure stamina and the ability to continue functioning when need be.

- General Cognitive Competence: In addition to one's ability to "learn new information and apply learned knowledge, logic, and reasoning for the purpose of understanding and solving problems" (Bar-On, 2016, p. 105), this scale appears to assess the capacity to learn more about the challenges one is faced with, to first understand them and then think about a reasonable course of action, to apply potentially effective solutions and weigh conflicting evidence, as well as to take into account the short-term and long-term consequences of potential solutions being considered.

- Key Cognitive Competencies: This composite scale ${ }^{5}$ was created to measure a factor that emerged from EFA, which appears to collectively assesses the following six subfactors that are important contributors to effective cognitive functioning:

- Coping and Endurance: In addition to "managing one's feelings in stressful situations" in order to function effectively while remaining relatively calm (Bar-On, 2016, p. 106), this sub-scale appears to assess how well people typically cope and function under pressure. This includes evaluating how effective they are in dealing with anxietyprovoking situations.

- Situational Awareness: In addition to "evaluating the immediate situation, paying attention to detail as well as understanding, clarifying, and closing gaps between the perception of subjective reality and objective reality" (BarOn, 2016, p. 105), this sub-scale assesses how attentive people are to their surroundings and how well they size up the situation. This appears to be based on an ability to update their assessment of situations in response to changes in the immediate environment as well as to filter out irrelevant information, in order not to get distracted.

- Flexibility: In addition to "coping with and adapting to change as well as dealing with unexpected, unpredictable and confusing situations" (Bar-On, 2016, p. 105), this subscale assesses the ability to flexibly "think on one's feet" and deal with the unexpected, finding ways to improvise and adapt when the unpredictable occurs, and to make the necessary adjustments to overcome. This often requires one

${ }^{5} \mathrm{~A}$ "composite scale" refers to a scale that comprises sub-scales (Key Cognitive Competencies, Finding Meaning and Acting Responsibly, and Motivational Drive); and a composite scale score is calculated by averaging its sub-scale scores. It is important to note that this is a descriptive rather than a statistical term. to re-reframe setbacks and not to see them as personal or permanent.

- Resourcefulness and Resilience: In addition to the ability "to be innovative and consider different ways of coping with situations" (Bar-On, 2016, p. 105), this sub-scale appears to assess the capacity of individuals to generate different approaches to dealing with challenges and setbacks as well as to resiliently recover from them. If previous approaches are ineffective, resourceful individuals typically come up with alternative approaches that work; and this often depends on formulating an effective course of action aimed at going from the current situation to a better one.

- Decision-Making: In addition to "generating potentially effective solutions to problems, weighing the pros and cons of each possibility and deciding on the best solution" (BarOn, 2016, p. 105), this sub-scale assesses the ability to make good decisions in general. Moreover, this scale measures the ability to come up with a potentially effective plan that requires coping with ambiguity and exercising sound judgement even when working under pressure and dealing with potential risks.

- Preparedness and Readiness: This sub-scale was created to measure a sub-factor that surfaced as a result of EFA. Based on the items that loaded on this sub-factor, this new sub-scale appears to assess the ability of individuals to be prepared and ready to cope with immediate situations that arise and/or to execute some form of goal-oriented action based on what they have learned. This includes immediately sizing up what is presently happening in the here-andnow, deciding on the best course of action and rapidly implementing it, which appears to be what is cognitively needed in dealing with emergency situations.

- Applying Experience: In addition to "appropriately and effectively applying past experience in order to facilitate current problem-analysis, problem-solving, and decisionmaking" (Bar-On, 2016, p. 105), this scale assesses the ability to apply experience in understanding and dealing with current challenges and problematic situations. This requires the capacity to effectively combine past experience with new information and approaches, which is an important contributor to effective cognitive functioning.

- Self-Control: In addition to "controlling emotions and maintaining self-composure" (Bar-On, 2016, p. 106), this scale essentially assesses "the ability of people to control their emotions so they work for them and not against them." Moreover, it evaluates the ability to effectively deal with challenges while maintaining outward composure.

- Self-Reliance: In addition to "being independent from others and being able to think things out alone, make decisions and act independently when needed" (Bar-On, 2016, p. 105), this scale essentially assesses the capacity to think and act independently rather than depending on others. It evaluates the ability of people to act alone when need be, even though they are open to receiving input and suggestions from others.

- Decisiveness: In addition to "expressing oneself openly, clearly and boldly" as well as "being able to confidently convey 
feelings, beliefs, and ideas" (Bar-On, 2016, p. 105), this scale assesses the ability of people to be assertive and decisive as well as to set firm limits with others when necessary but without being aggressive or hostile.

- Courage: In addition to being able "to overcome one's apprehensions and fears to act courageously" (Bar-On, 2016, p. 105-106), this scale was designed to measure the capability of individuals to protect, stand up for and support others even when there might be negative consequences for doing so. Additionally, this scale also evaluates the extent to which people are even prepared to risk their life to save another person's life.

- Social Awareness: In addition to "being aware of others, their feelings and concerns which helps one interact with people and become a more cooperative, constructive, and contributing team player" (Bar-On, 2016, p. 106), this scale assesses the ability to understand non-verbal communication, to know how others feel and to be attentive to their needs.

- Connectedness: In addition to "being able to connect with other people and to establish and maintain mutually satisfying interpersonal relationships" (Bar-On, 2016, p. 106), this scale appears to evaluate the capacity to establish and maintain good relationships with others, get along with friends and colleagues as well as to enjoy social interactions in general.

- Finding Meaning and Acting Responsibly: This is a composite scale that was created to measure a factor that emerged from EFA, that assesses the following two sub-factors that are thought to be important contributors to finding meaning in what one does which also benefits others as well as oneself in a socially responsible manner:

- Meaningfulness: In addition to "finding meaning in what one does as well as being passionately involved in meaningful pursuits that benefit others in addition to oneself" (Bar-On, 2016, p. 106), this sub-scale appears to assess the ability to live a meaningful and rewarding life.

- Social Responsibility: In addition to "living according to a set of principles, values, and beliefs which guide one's decisions and ability to do the right thing" (Bar-On, 2016, p. 106), this sub-scale appears to assess the consistency of one's moral integrity when one is with family members, friends and/or colleagues. Fundamentally, this is based on the ability to understand the difference between right and wrong and to act accordingly.

- Engagement: In addition to "being committed to one's work which builds on feeling passionate about what one enjoys doing" that enhances overall motivational drive (Bar-On, 2016, p. 106), this scale assesses the degree to which people feel positive about what they do or have done and understand the positive impact it has or might have on others.

- Motivational Drive: This is a composite scale that was created to measure a factor that emerged from EFA, which collectively assesses the following three sub-factors that are thought to be important contributors to one's overall motivational drive that significantly impacts performance:
- Self-Motivation: In addition to "being positive, optimistic, and energized in doing what one does" (Bar-On, 2016, p. 106), this sub-scale assesses the degree to which people are capable of motivating themselves. This enhances their drive to get as much as they can out of what they enjoy doing and energizes them to perform on an even higher level.

- Determination: In addition to "being committed to decisions that are made and goals that are set as well as being determined to follow through with them" (Bar-On, 2016, p. 106), this sub-scale appears to assess how resolute people are in the choices and decisions they make. This essentially requires the resolve to begin what they decide to do and to move into action mode after decisions are made.

- Perseverance: In addition to "persevering and following through with a task until it is completed" (Bar-On, 2016, p. 106), this sub-scale also assesses the drive to pursue goals in general.

\section{MMP3 ${ }^{\text {TM's }}$ Basic Psychometric Properties}

Subsequent to obtaining an estimate of $\mathrm{MMP}^{\mathrm{TM}}$ 's factorial structure and what it appears to assess based on the highest loading items, the basic psychometric properties of this developing questionnaire were then examined by evaluating the scale score means, standard deviations, standard error of means, skewness, and kurtosis. The results are presented in Table 2A. Mean scores for males and females as well as for five different age groups were also examined for significant differences, and the results are presented in Tables $\mathbf{2 B}, \mathbf{C}$ respectively. It is important to note that mean scores appear in percentages, in that the response options were formatted in percentages ranging from 0 to $100 \%$ as was previously described in the Methodology section. To reiterate moreover, the term "composite score" is descriptively used to refer to the following three scale scores that were created by averaging the sub-scales that they comprise: (1) Key Cognitive Competencies; (2) Finding Meaning and Acting Responsibly; and (3) Motivational Drive.

In that the skewness and kurtosis of all of the composite scales, scales and sub-scales fall within the acceptable \pm 2.0 range (Trochim and Donnelly, 2014), the mean scores in Table 2A appear to be normally distributed. Moreover, the standard error of the means obtained for the scale scores suggests it is expected that similar results would be obtained from other samples from the same population (Tabachnick and Fidell, 2001; Barde and Prajakt, 2012). The mean scores, however, appear to be relatively high, substantially above an expected middle range, which suggests a need to adjust raw scores proportionally downward. Subsequent to collecting data from larger and more diverse samples across cultures, this will eventually be done by multiplying raw scores by non-standardized beta weights obtained from applying MRA in order to first examine the degree of correlation between the major scale scores and the validity scale score that attempts to assess social response bias. The software, used to score the responses, will then be programmed to automatically and proportionally reduce significantly high raw scores by converting them to adjusted scores thus improving the 
TABLE 2A | The basic psychometric properties of the MMP3 ${ }^{T M}$, including mean scores and standard deviations (SD) in percentages, standard error of means (SEM), skewness (Skew.), and kurtosis (Kurt.), based on the normative sample ( $n=2,380)$.

\begin{tabular}{|c|c|c|c|c|c|}
\hline MMP3 $^{T M}$ scales & Mean (\%) & $S D(\%)$ & SEM & Skew. & Kurt. \\
\hline 1. Physical Fitness and Well-Being & 68.1 & 17.7 & 0.51 & -0.44 & -0.05 \\
\hline 2. Discomfort Tolerance and Stamina & 71.8 & 14.5 & 0.42 & -0.48 & 0.11 \\
\hline 3. General Cognitive Competence & 76.8 & 13.3 & 0.38 & -0.58 & 0.68 \\
\hline 4. Key Cognitive Competencies & 73.9 & 13.5 & 0.39 & -0.60 & 1.00 \\
\hline 4.1 Coping and Endurance & 72.9 & 17.3 & 0.50 & -0.74 & 0.82 \\
\hline 4.2 Situational Awareness & 72.9 & 14.1 & 0.41 & -0.52 & 0.74 \\
\hline 4.3 Flexibility & 74.0 & 15.1 & 0.44 & -0.68 & 1.26 \\
\hline 4.4 Resourcefulness and Resilience & 74.0 & 14.9 & 0.43 & -0.37 & 0.12 \\
\hline 4.5 Decision-Making & 74.0 & 14.9 & 0.43 & -0.45 & 0.49 \\
\hline 4.6 Preparedness and Readiness & 75.4 & 15.5 & 0.45 & -0.65 & 0.45 \\
\hline 5. Applying Experience & 80.2 & 13.9 & 0.40 & -0.79 & 1.23 \\
\hline 6. Self-Control & 73.0 & 15.2 & 0.44 & -0.52 & 0.37 \\
\hline 7. Self-Reliance & 70.9 & 13.6 & 0.39 & -0.45 & 0.54 \\
\hline 8. Decisiveness & 67.3 & 15.3 & 0.44 & -0.51 & 0.35 \\
\hline 9. Courage & 68.8 & 15.6 & 0.45 & -0.23 & -0.38 \\
\hline 10. Social Awareness & 72.2 & 13.9 & 0.40 & -0.46 & 0.51 \\
\hline 11. Connectedness & 73.4 & 14.6 & 0.42 & -0.70 & 1.23 \\
\hline 12. Finding Meaning and Acting Responsibly & 82.4 & 12.2 & 0.35 & -0.95 & 1.57 \\
\hline 12.1 Meaningfulness & 80.6 & 14.3 & 0.42 & -0.84 & 1.01 \\
\hline 12.2 Social Responsibility & 84.2 & 12.7 & 0.37 & -1.05 & 1.64 \\
\hline 13. Engagement & 76.3 & 17.2 & 0.50 & -0.87 & 0.75 \\
\hline 14. Motivational Drive & 79.2 & 13.7 & 0.40 & -0.82 & 0.93 \\
\hline 14.1 Self-Motivation & 79.2 & 14.6 & 0.42 & -0.88 & 1.19 \\
\hline 14.2 Determination & 78.8 & 15.0 & 0.43 & -0.71 & 0.42 \\
\hline 14.3 Perseverance & 79.6 & 14.6 & 0.42 & -0.79 & 0.61 \\
\hline
\end{tabular}

accuracy of the scores (i.e., raw scores adjusted through factoring out response bias).

While no significant differences were found in (a) general cognitive competence, (b) the ability to apply experience in coping with problems, (c) connecting with others, (d) finding meaning in one's work and acting responsibly, or in (e) motivational drive, significant gender differences are found in more than half of the scale scores appearing in Table 2B; and the majority of these scores were apparently higher for males in the North American samples examined. As such, gender-specific norms will be used in the future to score MMP3 ${ }^{\mathrm{TM}}$ responses in order to generate more accurate results (i.e., raw scores adjusted by factoring out gender interaction).

The results in Table $\mathbf{2 C}$ indicate that most contributors to performance tend to increase with age, which suggests that older people perform better than younger people in general. While this might be the results of experience-based wisdom, this will need to be empirically examined in future studies. In any event, agespecific norms will be used in scoring $\mathrm{MMP}^{\mathrm{TM}}$ responses in addition to gender-specific norms as was previously mentioned.

\section{MMP3 $^{\text {TM }}$ 's Reliability}

The primary approach used to estimate $\mathrm{MMP}^{\mathrm{TM}}$ 's reliability was to evaluate the internal consistency of its scales with Cronbach alphas; and the results are presented in Table 3.
The results in Table 3 suggest that all of the scales possess more than adequate reliability, based on the assumption that reliability coefficients equal to or greater than 0.70 indicate adequate reliability for scales and sub-scales (Anastasi, 1988; Tabachnick and Fidell, 2001) while coefficients equal to or greater than 0.80 are thought to be the minimum for composite scales which has been achieved in this study. These findings also justify the creation of sub-scales comprising as few as five items, as was previously mentioned (Hair et al., 2011). Furthermore, relatively high reliability coefficients usually predict that the scale's validity will be relatively high as well (Hill and Lewicki, 2006).

\section{MMP3 ${ }^{\text {TM's }}$ Validity}

Discriminant validity and predictive validity were examined with ANOVA and MRA respectively. In the ANOVA evaluation of $\mathrm{MMP}^{\mathrm{TM}}$ 's discriminant validity, a sample of high performers and low performers were compared for possible significant differences based on their self-reported performance ratings at work. High performers were those whose recent performance rating was self-reported to be equal to or greater than one standard deviation above the mean $(n=304)$, while low performers were those whose performance rating was equal to or less than one standard deviation from the mean $(n=292)$ as was previously explained in the Methodology section. Although "self-reported performance ratings" are most likely biased as 
TABLE 2B | The MMP3 ${ }^{T M}$ scale scores, in percentages, for males $(n=1,064)$ and females $(n=940)$, based on individuals who identified their gender when responding to the questionnaire.

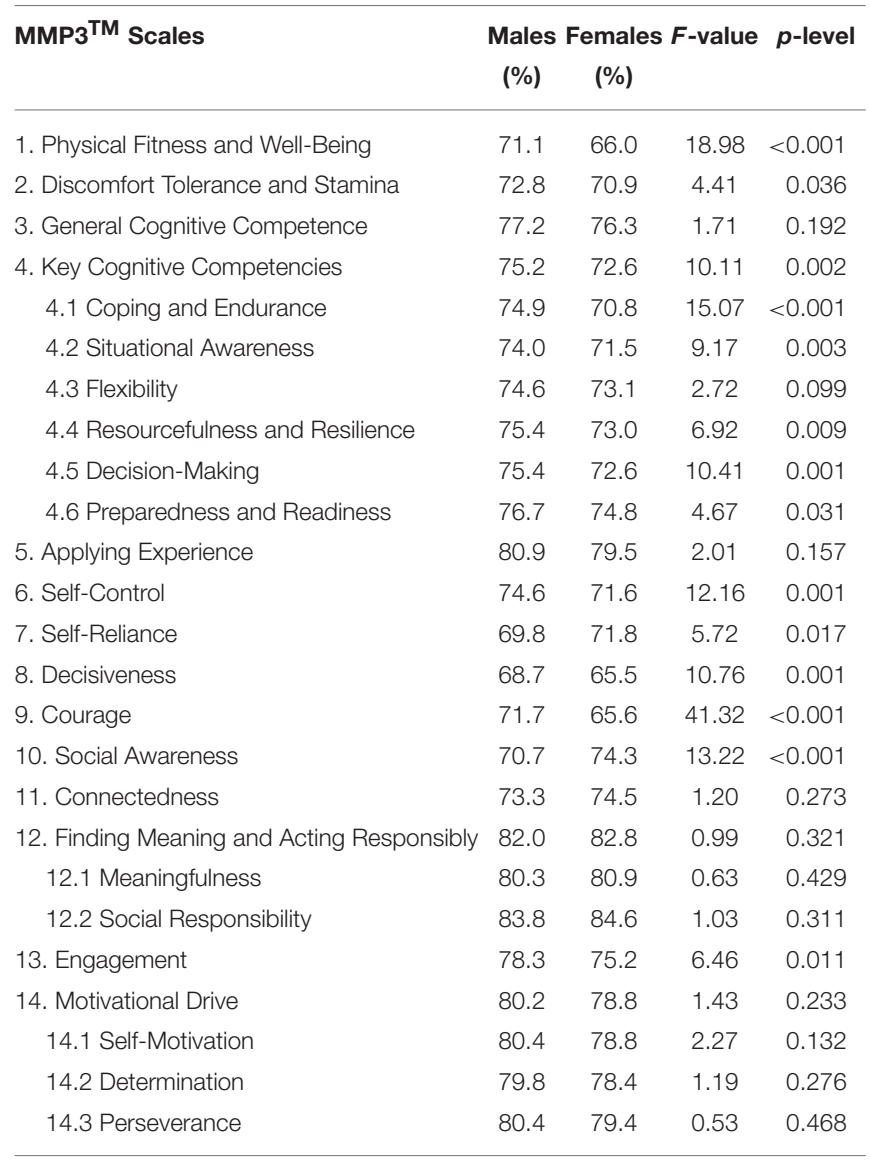

ANOVA was used to examine potential gender differences.

explained in that section, the method applied to calculate them may have provided a potentially accurate estimate of current occupational performance (which will need to be examined by more objective methods in future studies). The initial results for discriminatory validity are listed in Table 4. Additionally, predictive validity was evaluated by applying MRA to examine the ability of the MMP3 ${ }^{\mathrm{TM}}$ scores to predict self-reported performance $(n=1,788)$; and the results are presented in Table 5.

The findings in Table 4 indicate that nearly all of the MMP3 ${ }^{\mathrm{TM}}$ scales are capable of significantly discriminating between high and low performers in the present study, while the only scale that could not significantly discriminate between high and low performers was Self-Reliance for the population sample studied. Although this might justify the exclusion of this particular scale in the MMP3 ${ }^{\mathrm{TM}}$, it was decided, at least temporarily, to retain it based numerous studies that support the importance of selfreliance as a significant contributor to performance (Bar-On et al., 2006).

While the results in Table 4 indicate that nearly all of the MMP3 ${ }^{\mathrm{TM}}$ scales are capable of significantly distinguishing between high and low performers, the findings in Table 5 suggest that all of the scales, including Self-Reliance, are capable of predicting performance. These findings would appear to justify retaining the Self-Reliance scale in the questionnaire. Moreover, the overall multivariate correlation-i.e., the Multiple $\mathrm{R}$-between the MMP3 ${ }^{\mathrm{TM}}$ scales and self-reported performance is $0.56(F=7.39, p<0.001)$ suggesting that it possesses relatively high predictive validity; and this was expected from the scales' relatively high reliability as was previously mentioned. The three most robust predictors of performance appear to be situational awareness $(\beta=0.274, t=4.60, p<0.001)$, coping and endurance $(\beta=0.154, t=3.01, p=0.003)$, and engagement $(\beta=0.115$, $t=3.24, p=0.001)$.

In a recently approved doctoral dissertation (Conroy, 2017), Dr. Richard Conroy demonstrated that the factors assessed by the MMP3 ${ }^{\mathrm{TM}}$ adequately predict effective leadership. More succinctly, this instrument was shown to be a robust predictor of "transformational leadership" in a sample of 454 senior law enforcement officers. The predictive model that emerged, from Multiple Regression Analysis, indicated that most of the variance of this type of leadership can be significantly accounted for $[\mathrm{R}=0.76(F=35.00, p<0.001)]$ by the $\mathrm{MMP}^{\mathrm{TM}}$. A reexamination of the dataset suggests that its predictive ability is even greater than was originally thought.

\section{DISCUSSION}

\section{The Key Findings}

The key findings presented in this article suggest that the $M M P 3^{\mathrm{TM}}$ is a reliable and valid measure of performance including leadership. Moreover, this psychometric instrument has been methodically developed based on (1) a systematic search of the literature, (2) input from expert consultants who have worked in various aspects of human performance as well as (3) the application of multivariate statistics designed to examine its factorial structure, reliability and validity. Furthermore, the $\mathrm{MMP}^{\mathrm{TM}}$ addresses the need for developing more reliable and valid multifactor measures of performance in pre-employment testing. In addition to comprehensively assessing the potential for performance in the workplace, it is hoped that it can be applied elsewhere as is discussed below. The findings also suggest that three of the most robust predictors of occupational performance appear to be (1) possessing situational awareness and being attentive to detail, (2) being able to effectively cope with stress as well as (3) being totally engaged that significantly impacts one's motivational level. According to how these factors are described and assessed by the $\mathrm{MMP}^{\mathrm{TM}}$, this means that performance is driven by being attentive to one's immediate surroundings, paying attention to detail and not getting distracted. Additionally, effective performance also requires the ability to cope well with stress and function well under pressure. Last, high performers need to be engaged in their work and feel passionate about what they do in order to be sufficiently motivated to function at their best.

\section{The Importance of the Findings}

One of the most important findings revealed in this article is that the MMP $3^{\mathrm{TM}}$ is capable of concomitantly assessing five different groups of significant contributors to performance, comprising 


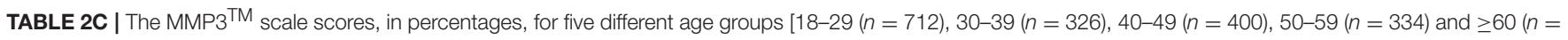
138)] based on individuals who identified their age when responding to the questionnaire.

\begin{tabular}{|c|c|c|c|c|c|c|c|}
\hline MMP3 $^{\mathrm{TM}}$ scales & $18-29(\%)$ & $30-39(\%)$ & $40-49(\%)$ & $50-59(\%)$ & $\geq 60(\%)$ & $F$-value & $p$-level \\
\hline 1. Physical Fitness and Well-Being & 72.5 & 66.3 & 63.7 & 67.9 & 72.2 & 9.64 & $<0.001$ \\
\hline 2. Discomfort Tolerance and Stamina & 72.1 & 70.5 & 71.3 & 72.1 & 75.6 & 1.47 & 0.211 \\
\hline 3. General Cognitive Competence & 75.5 & 77.1 & 76.2 & 79.6 & 79.3 & 3.57 & 0.007 \\
\hline 4. Key Cognitive Competencies & 72.7 & 73.3 & 74.0 & 76.8 & 76.7 & 3.51 & 0.007 \\
\hline 4.1 Coping and Endurance & 71.1 & 71.9 & 73.7 & 76.3 & 77.0 & 3.65 & 0.006 \\
\hline 4.2 Situational Awareness & 72.5 & 71.1 & 72.8 & 74.9 & 76.2 & 2.29 & 0.058 \\
\hline 4.3 Flexibility & 71.6 & 73.5 & 75.0 & 77.4 & 76.1 & 5.03 & 0.001 \\
\hline 4.4 Resourcefulness and Resilience & 73.0 & 74.2 & 73.0 & 77.9 & 75.8 & 3.69 & 0.005 \\
\hline 4.5 Decision-Making & 72.4 & 73.7 & 73.9 & 77.1 & 77.0 & 3.45 & 0.008 \\
\hline 4.6 Preparedness and Readiness & 75.5 & 75.1 & 75.4 & 77.5 & 78.2 & 1.00 & 0.408 \\
\hline 5. Applying Experience & 78.5 & 80.6 & 80.9 & 82.5 & 82.5 & 2.93 & 0.020 \\
\hline 6. Self-Control & 73.3 & 70.7 & 73.0 & 74.8 & 76.2 & 2.10 & 0.079 \\
\hline 7. Self-Reliance & 67.7 & 70.5 & 72.5 & 72.1 & 74.7 & 7.05 & $<0.001$ \\
\hline 8. Decisiveness & 66.5 & 66.0 & 66.9 & 69.5 & 67.7 & 1.29 & 0.273 \\
\hline 9. Courage & 66.6 & 66.2 & 70.1 & 73.0 & 73.6 & 8.25 & $<0.001$ \\
\hline 10. Social Awareness & 69.8 & 73.5 & 73.7 & 74.6 & 72.6 & 4.70 & 0.001 \\
\hline 11. Connectedness & 75.1 & 71.7 & 72.9 & 74.9 & 74.5 & 2.09 & 0.080 \\
\hline 12. Finding Meaning and Acting Responsibly & 79.6 & 81.5 & 84.1 & 86.2 & 86.0 & 11.96 & $<0.001$ \\
\hline 12.1 Meaningfulness & 78.9 & 79.0 & 81.7 & 83.7 & 83.8 & 4.87 & 0.001 \\
\hline 12.2 Social Responsibility & 80.3 & 84.0 & 86.5 & 88.8 & 88.2 & 18.42 & $<0.001$ \\
\hline 13. Engagement & 77.7 & 75.0 & 73.3 & 79.5 & 81.4 & 4.92 & 0.001 \\
\hline 14. Motivational Drive & 81.2 & 77.4 & 77.3 & 79.8 & 83.2 & 4.84 & 0.001 \\
\hline 14.1 Self-Motivation & 82.2 & 77.3 & 76.5 & 79.8 & 81.5 & 6.58 & $<0.001$ \\
\hline 14.2 Determination & 80.0 & 77.0 & 77.4 & 80.0 & 83.5 & 3.29 & 0.011 \\
\hline 14.3 Perseverance & 81.4 & 77.9 & 78.0 & 79.7 & 84.5 & 4.12 & 0.003 \\
\hline
\end{tabular}

ANOVA was used to examine potential age differences.

a total of 22 factors, including the following: (1) two physical factors; (2) eight cognitive factors; (3) four intra-personal factors; (4) three inter-personal factors; and (5) five motivational factors. In addition to confirming more that $80 \%$ of the ideas presented in the author's previous publication moreover (Bar-On, 2016), the results presented here empirically support the importance of physical (Boles et al., 2004; Fritz and Sonnentag, 2005; Meerding et al., 2005; Conn et al., 2009; Pronk and Kottke, 2009), cognitive (Motowidlo et al., 1986; Mento et al., 1987; Pearson, 1987; Janssen and Van Yperen, 2004; Cote and Miners, 2006; Hill and Lewicki, 2006), intra-personal (Motowidlo et al., 1986; Matteson and Ivancevich, 1987; Sullivan and Bhagat, 1992; Kuncel et al., 2004; Bar-On et al., 2006; Martinuzzi, 2009), interpersonal (Babin and Boles, 1996; Schwepker and Ingram, 1996; Van Scotter and Motowidlo, 1996; Janssen and Van Yperen, 2004; Lennick and Kiel, 2007; Baker and O'Malley, 2008; Hsu, 2008), and motivational (Weitz et al., 1986; Cotton, 1993; Becker et al., 1996; Diefendorff et al., 2002; Locke and Latham, 2002; Halbesleben and Wheeler, 2008; Markos and Sridevi, 2010; Rich et al., 2010) predictors of performance proposed by others; and this, in turn, appears to help validate what the MMP3 ${ }^{\mathrm{TM}}$ assesses as well. This also empirically confirms the value of combining the above-mentioned groups of contributors to better predict performance, which justifies the importance of developing a multifactor conceptual and psychometric model that is designed to comprehensively evaluate the whole person when attempting to study, assess and enhance human behavior and performance.

The novelty of the MMP3 ${ }^{\mathrm{TM}}$, as well as this publication in the professional literature, is that the above-mentioned five different groups of contributors to performance can be assessed by employing only one psychometric instrument, thus reducing the need to combine various different instruments to evaluate all of these key factors; and this, in turn, is expected to reduce the time and cost involved in psychological testing.

In addition to its assessment component, it is important to emphasize that the MMP3 ${ }^{\mathrm{TM}}$ has a development component that will automatically provide a number of suggestions for strengthening the individuals' weakest contributors to performance indicated by their lowest scores. Thus, the MMP3 ${ }^{\mathrm{TM}}$ can be contextualized as a comprehensive operational framework designed to help understand why some people perform better than others and to determine which contributing factors need to be strengthened in order to enhance performance in individuals who are underperforming.

Depending upon the outcome of future predictive validity and incremental validity studies, it is possible that the MMP3 ${ }^{\mathrm{TM}}$ will compare favorably with other psychometric instruments used to predict performance in the workplace and elsewhere. This is, 
TABLE 3 | The internal consistency reliability of the MMP3 ${ }^{T M}$ scales, based on the normative sample $(n=2,380)$.

\begin{tabular}{lc}
\hline MMP3 $^{\text {TM }}$ scales & Cronbach alphas \\
\hline 1. Physical Fitness and Well-Being & 0.86 \\
2. Discomfort Tolerance and Stamina & 0.73 \\
3. General Cognitive Competence & 0.80 \\
4. Key Cognitive Competencies & 0.96 \\
4.1 Coping and Endurance & 0.87 \\
4.2 Situational Awareness & 0.73 \\
4.3 Flexibility & 0.78 \\
4.4 Resourcefulness and Resilience & 0.80 \\
4.5 Decision-Making & 0.84 \\
4.6 Preparedness and Readiness & 0.82 \\
5. Applying Experience & 0.86 \\
6. Self-Control & 0.87 \\
7. Self-Reliance & 0.72 \\
8. Decisiveness & 0.81 \\
9. Courage & 0.77 \\
10. Social Awareness & 0.79 \\
11. Connectedness & 0.82 \\
12. Finding Meaning and Acting Responsibly & 0.84 \\
12.1 Meaningfulness & 0.79 \\
12.2 Socially Responsible & 0.74 \\
13. Engagement & 0.88 \\
14. Motivational Drive & 0.93 \\
14.1 Self-Motivation & 0.78 \\
\hline
\end{tabular}

cautiously, based on what has been presented here compared with findings from other publications describing the predictive validity of most pre-employment testing involving cognitive factors and personality traits for example. More specifically, the present article revealed a predictive coefficient of 0.56 suggesting that the MMP3 ${ }^{\mathrm{TM}}$ scales are capable of assessing more than $30 \%$ of the variance that explains occupational performance accounting for nearly a third of the factors that predict performance in the workplace which is significant in the field of test-construction. These findings suggest that the $\mathrm{MMP}^{\mathrm{TM}}$ could be a potentially valuable and desirable tool when this is compared with the results of very large meta-analyses that have been conducted on the predictive ability of cognitive and personality tests. More succinctly, Morgeson and his colleagues reported findings from 13 meta-analyses $(n=40,230)$ indicating that the average predictive coefficient of cognitive testing is 0.25 accounting for only $6 \%$ of the variance of occupational performance (Morgeson et al., 2007, p. 700); and based on 12 meta-analyses $(n=23,413)$, the average predictive coefficient of personality traits is only 0.15 accounting for a mere $2 \%$ of the variance (Morgeson et al., 2007, p. 705).

The importance of the $M M P 3^{\mathrm{TM}}$, as an assessment, development and research instrument, will depend on the extent to which it will be applied and the degree to which it will help improve human performance. If it can be effectively applied
TABLE 4 | The ability of the MMP3 ${ }^{\mathrm{TM}}$ to distinguish between high performers $(n=304)$ and low performers $(n=292)$, examined by applying ANOVA with gender and age designated as co-variates.

\begin{tabular}{|c|c|c|c|c|}
\hline $\mathrm{MMP}^{\mathrm{TM}}$ scales & $\begin{array}{c}\text { High } \\
\text { (\%) }\end{array}$ & $\begin{array}{c}\text { Low } \\
(\%)\end{array}$ & $F$-value & p-level \\
\hline 1. Physical Fitness and Well-Being & 77.0 & 63.9 & 22.18 & $<0.001$ \\
\hline 2. Discomfort Tolerance and Stamina & 75.9 & 67.7 & 12.65 & 0.005 \\
\hline 3. General Cognitive Competence & 82.0 & 70.3 & 38.68 & $<0.001$ \\
\hline 4. Key Cognitive Competencies & 80.7 & 65.6 & 56.75 & $<0.001$ \\
\hline 4.1 Coping and Endurance & 80.6 & 61.9 & 47.62 & $<0.001$ \\
\hline 4.2 Situational Awareness & 80.0 & 64.1 & 59.15 & $<0.001$ \\
\hline 4.3 Flexibility & 78.3 & 66.4 & 27.78 & $<0.001$ \\
\hline 4.4 Resourcefulness and Resilience & 80.6 & 67.4 & 35.56 & $<0.001$ \\
\hline 4.5 Decision-Making & 81.3 & 66.3 & 50.05 & $<0.001$ \\
\hline 4.6 Preparedness and Readiness & 83.7 & 67.7 & 50.26 & $<0.001$ \\
\hline 5. Applying Experience & 82.1 & 76.6 & 10.32 & 0.003 \\
\hline 6. Self-Control & 79.7 & 65.2 & 39.94 & $<0.001$ \\
\hline 7. Self-Reliance & 69.9 & 71.5 & 0.69 & 0.408 \\
\hline 8. Decisiveness & 72.0 & 62.2 & 19.67 & $<0.001$ \\
\hline 9. Courage & 71.8 & 62.2 & 22.81 & $<0.001$ \\
\hline 10. Social Awareness & 75.1 & 67.5 & 18.02 & $<0.001$ \\
\hline 11. Connectedness & 79.0 & 67.4 & 28.78 & $<0.001$ \\
\hline 12. Finding Meaning and Acting Responsibly & 86.7 & 77.1 & 33.55 & $<0.001$ \\
\hline 12.1 Meaningfulness & 85.0 & 75.3 & 24.99 & $<0.001$ \\
\hline 12.2 Social Responsibility & 88.3 & 78.8 & 30.49 & $<0.001$ \\
\hline 13. Engagement & 83.5 & 69.4 & 33.66 & $<0.001$ \\
\hline 14. Motivational Drive & 86.1 & 73.1 & 41.61 & $<0.001$ \\
\hline 14.1 Self-Motivation & 86.4 & 72.4 & 41.76 & $<0.001$ \\
\hline 14.2 Determination & 85.6 & 73.8 & 28.49 & $<0.001$ \\
\hline 14.3 Perseverance & 86.3 & 73.3 & 36.78 & $<0.001$ \\
\hline
\end{tabular}

in one or more of the following areas and prove to be useful moreover, it is reasonable to assume that it will demonstrate both importance and value as an operational model of performance: (1) parenting; (2) education; (3) human resources; (4) healthcare; and (5) research designed to study and improve performance. These potential applications were described, in detail, by the author in his first publication on the Multifactor Measure of Performance $^{\mathrm{TM}}$ (Bar-On, 2016, p. 113-115). An additional application of this psychometric instrument is currently being examined for the purpose of assessing and training emergency responders and managers, aimed at enhancing their performance in natural and man-made disasters. The author is currently working with Professor Isaac Ashkenazi, an internationally acknowledged expert in this field, to develop a customized version of the $\mathrm{MMP}^{\mathrm{TM}}$ which will include a VR (Virtual Reality) application designed to facilitate the assessment and development of emergency managers and crisis leaders.

If one takes into account the above-mentioned features, psychometric strengths and potential applications of the $M M P 3^{\mathrm{TM}}$, these would be the primary reasons for practitioners and researchers to apply this assessment and development instrument. To verify the potential of the MMP3 ${ }^{\mathrm{TM}}$ however, additional studies will need to be conducted on larger and 
TABLE 5 | The ability of the MMP3 ${ }^{\mathrm{TM}}$ to predict performance, based on applying MRA to examine the degree of correlation between its scale scores and self-reported performance at work $(n=1,788)$.

\begin{tabular}{|c|c|c|c|}
\hline MMP3 $^{\text {TM }}$ scales & Multiple R & $F$-value & $p$-level \\
\hline 1. Physical Fitness and Well-Being & 0.23 & 18.78 & $<0.001$ \\
\hline 2. Discomfort Tolerance and Stamina & 0.26 & 36.97 & $<0.001$ \\
\hline 3. General Cognitive Competence & 0.33 & 40.64 & $<0.001$ \\
\hline 4. Key Cognitive Competencies & 0.43 & 18.64 & $<0.001$ \\
\hline 4.1 Coping and Endurance & 0.35 & 47.78 & $<0.001$ \\
\hline 4.2 Situational Awareness & 0.37 & 39.27 & $<0.001$ \\
\hline 4.3 Flexibility & 0.29 & 24.02 & $<0.001$ \\
\hline 4.4 Resourcefulness and Resilience & 0.25 & 16.74 & $<0.001$ \\
\hline 4.5 Decision-Making & 0.32 & 28.20 & $<0.001$ \\
\hline 4.6 Preparedness and Readiness & 0.31 & 21.63 & $<0.001$ \\
\hline 5. Applying Experience & 0.23 & 11.23 & $<0.001$ \\
\hline 6. Self-Control & 0.31 & 18.38 & $<0.001$ \\
\hline 7. Self-Reliance & 0.25 & 16.84 & $<0.001$ \\
\hline 8. Decisiveness & 0.21 & 22.81 & $<0.001$ \\
\hline 9. Courage & 0.26 & 14.91 & $<0.001$ \\
\hline 10. Social Awareness & 0.22 & 10.53 & $<0.001$ \\
\hline 11. Connectedness & 0.30 & 14.21 & $<0.001$ \\
\hline 12. Finding Meaning and Acting Responsibly & 0.33 & 15.81 & $<0.001$ \\
\hline 12.1 Meaningfulness & 0.26 & 17.82 & $<0.001$ \\
\hline 12.2 Social Responsibility & 0.29 & 31.54 & $<0.001$ \\
\hline 13. Engagement & 0.26 & 18.36 & $<0.001$ \\
\hline 14. Motivational Drive & 0.32 & 16.74 & $<0.001$ \\
\hline 14.1 Self-Motivation & 0.29 & 22.80 & $<0.001$ \\
\hline 14.2 Determination & 0.24 & 21.35 & $<0.001$ \\
\hline 14.3 Perseverance & 0.29 & 46.31 & $<0.001$ \\
\hline
\end{tabular}

more diverse population samples aimed at examining its discriminatory, predictive and incremental validity. Future studies will also need to address the potential limitations of the present study that are discussed below.

\section{Limitations of the Present Research and the Need for Future Studies}

One of the basic approaches used in developing the Multifactor Measure of Performance ${ }^{\mathrm{TM}}$ also represents one of its potential limitations. More specifically, the contributors to performance that this questionnaire was designed to measure were those that were reviewed in the literature by the author who selected those he thought to be the key contributors to performance. It is reasonable to assume that other researchers would have reviewed the literature differently, possibly would have selected other predictors and might have also defined them definitely. Additionally, others might have decided to combine what were perceived to be similar factors and divide other factors into two or more separate factors. It is therefore important to receive additional input on the author's approach to developing this particular model.

Another potential limitation of the present study was not including more experts in the field, who could have provided additional ideas regarding important contributors to and predictors of performance, their description of these factors and selection of items designed to assess them.

It is also important to note that additional $\mathrm{MMP}^{\mathrm{TM}}$ data are currently being collected by the author, colleagues and other researchers; and results from these and future studies might or might not confirm this questionnaire's estimated factorial structure, psychometric properties, and strengths as presented in this article.

To reiterate, the $\mathrm{MMP}^{\mathrm{TM}}$ will need to be examined on larger and more diverse population samples across cultures. In order to receive a clearer and more accurate picture of the $\mathrm{MMP}^{\mathrm{TM}}$ 's factorial structure, CFA will be conducted after the author has obtained data from significantly larger samples. In addition to more extensively examining factorial structure and validity, the MMP3 ${ }^{\mathrm{TM}}$ 's discriminant, predictive and, especially, incremental validity studies will also need to be conducted as was previously mentioned.

An additional limitation of the current study can be seen in the way in which the MMP3 ${ }^{\mathrm{TM}}$ 's predictive validity has been examined. While the approach applied to estimate occupational performance, described in the data collection section, provided an approximation of how the subjects might be performing, it therefore has limitations and will eventually require the use of more objective methods in future studies such as (1) actual performance ratings completed by supervisors and co-workers as well as (2) comparing criterion groups of identified high and low performers for significant differences. Furthermore, future research will need to examine what types of human behavior and performance the MMP $3^{\mathrm{TM}}$ predicts and how well. In addition to general occupational performance, its ability to predict and improve teamwork and leadership will be studied as well. Additionally, its ability to evaluate and enhance parenting, academic performance as well as physical and psychological health will also need to be researched. Test-retest reliability studies will also need to be conducted in addition to MMP3 ${ }^{\mathrm{TM}}$ 's internal consistency reliability which was examined in the present article.

In that the norming and validation of psychometric instruments is a very lengthy process, it will take time before MMP3 ${ }^{\mathrm{TM}}$ 's exact structure, reliability and validity can be more fully understood; and the author welcomes researchers, students, and practitioners to apply and examine the MMP3 ${ }^{\mathrm{TM}}$ in future studies to help facilitate its continued norming, validation and application. The author plans to have the questionnaire translated from English to a number of different languages, which will both facilitate its continued norming and validation in order to continue studying the key contributors to performance as well as potentially expand its applicability.

\section{AUTHOR CONTRIBUTIONS}

$\mathrm{RB}-\mathrm{O}$ is the author of this paper, which is his "Inaugural Article" as an Associate Editor in the Organizational Psychology Section of Frontiers in Psychology. His professional background and interest focuses on the study, development and application of multifactor models and measures of 
performance. Since 1978, he has developed 12 different psychometric instruments designed to assess and develop various aspects of human performance including the Emotional Quotient Inventory ${ }^{\mathrm{TM}}\left(\mathrm{EQ}-\mathrm{i}^{\mathrm{TM}}\right)$. This article describes the Multifactor Measure of Performance ${ }^{\mathrm{TM}}\left(\mathrm{MMP}^{\mathrm{TM}}\right)$, which was

\section{REFERENCES}

Anastasi, A. (1988). Psychological Testing, 6th Edn. New York, NY: Macmillan Publishing.

Babin, B. J., and Boles, J. S. (1996). The effects of perceived co-worker involvement and supervisor support on service provider role stress, performance and job satisfaction. J. Retail. 72, 57-75. doi: 10.1016/S0022-4359(96)90005-6

Baker, W. F., and O'Malley, M. (2008). Leading with Kindness: How Good People Consistently Get Superior Results. New York, NY: AMACOM.

Barde, M. P., and Prajakt, J. B. (2012). What to use to express the variability of data: standard deviation or standard error of mean? Perspect. Clin. Res. 3, 113-116. doi: 10.4103/2229-3485.100662

Bar-On, R. (1988). The Development of a Concept of Psychological Well-Being. Doctoral dissertation, Rhodes University, Grahamstown.

Bar-On, R. (1997). The Bar-On Emotional Quotient Inventory (EQ-i): Technical Manual. Toronto, ON: Multi-Health Systems.

Bar-On, R. (2000). "Emotional and social intelligence: insights from the Emotional Quotient Inventory (EQ-i)," in Handbook of Emotional Intelligence: Theory, Development, Assessment and Application at Home, School and in the Workplace, eds R. Bar-On and J. D. A. Parker (San Francisco, CA: Jossey-Bass), 363-388.

Bar-On, R. (2004). “The Bar-On Emotional Quotient Inventory (EQ-i): rationale, description, and summary of psychometric properties," in Measuring Emotional Intelligence: Common Ground and Controversy, ed G. Geher (Hauppauge, NY: Nova Science Publishers), 111-142.

Bar-On, R. (2006). The Bar-On model of emotional-social intelligence. Psicothema 18, 13-25. Available online at: http://www.psicothema.com

Bar-On, R. (2016). "Beyond IQ \& EQ: the Bar-On multifactor model of performance," in The Wiley Handbook of Personality Assessment, ed U. Kumar (London: John Wiley \& Sons), 104-118.

Bar-On, R., Handley, R., and Fund, S. (2006). “The impact of emotional intelligence on performance," in Linking Emotional Intelligence and Performance at Work, eds V.U. Druskat, F. Sala, and G. Mont (Mahwah, NJ: Lawrence Erlbaum Associates), 3-19.

Becker, T. E., Billings, R. S., Eveleth, D. M., and Gilbert, N. L. (1996). Foci and bases of employee commitment: implications for job performance. Acad. Manag. J. 39, 464-482. doi: $10.2307 / 256788$

Bergkvist, L., and Rossiters, R. (2007). The predictive validity of multiple-item versus single-item measures of the same construct. J. Market. Res. 44, 175-184. doi: $10.1509 / j m k r .44 .2 .175$

Boles, M., Pelletier, B., and Lynch, W. (2004). The relationship between health risks and work productivity. J. Occupat. Environ. Med. 46, 737-745. doi: 10.1097/01.jom.0000131830.45744.97

Bryant, F. B., and Yarnold, P. R. (1995). "Principal-components analysis and confirmatory factor analysis," in Reading and Understanding Multivariate Statistics, eds L. G. Grimm and P. R. Yarnold (Washington, DC: American Psychology Association), 99-136.

Brown, J. D. (2009). Choosing the right type of rotation in PCA and EFA. JALT Testing Eval. SIG Newslett. 13, 20-25. Available online at: https://jalt.org/signews/testing-evaluation

Carlson, J. F., Geisinger, K. F., and Jonson, J. L. (2017). The Twentieth Mental Measurements Yearbook. Lincoln, NE: Buros Center for Testing.

Cattell, R. B. (1978). The Scientific Use of Factor Analysis. New York, NY: Plenum.

Cattell, R. B. (1952). Factor Analysis: An Introduction and Manual for the Psychologist and Social Scientist. New York, NY: Harper and Brothers.

Conn, V. S., Hafdahl, A. R., Cooper, P. S., Brown, L. M., and Lusk, S. L. (2009). Meta-analysis of workplace physical activity interventions. Am. J. Prevent. Med. 37, 330-339. doi: 10.1016/j.amepre.2009.06.008 developed to comprehensively measure and enhance what RB-O identified as key contributors to human performance. The MMP ${ }^{\mathrm{TM}}$, the concept it was designed to measure and the research involved in developing it are described in detail.

Conroy, R. J. (2017). Beyond Emotional Intelligence: A Correlational Study of Multifactor Measures of Performance and Law Enforcement Leadership Styles. An Unpublished Doctoral Dissertation Approved By Dallas Baptist University (US) in November 2017.

Cote, S., and Miners, C. T. H. (2006). Emotional intelligence, cognitive intelligences, and job performance. Adm. Sci. Q. 51, 1-28. doi: 10.2189/asqu.51.1.1

Cotton, J. L. (1993). Employee Involvement: Methods for Improving Performance and Work Attitudes. Thousand Oaks, CA: Sage Publications, Inc.

Diefendorff, J. M., Brown, D. J., Kamin, A. M., and Lord, R. G. (2002). Examining the roles of job involvement and work centrality in predicting organizational citizenship behaviors and job performance. J. Organ. Behav. 23, 93-108. doi: $10.1002 /$ job. 123

Drolet, A. L., and Morrison, D. G. (2001). Do we really need multipleitem measures in service research? J. Serv. Res. 3, 196-204. doi: 10.1177/109467050133001

Fritz, C., and Sonnentag, S. (2005). Recovery, health, and job performance: effects of weekend experiences. J. Occup. Health Psychol. 10, 187-199. doi: 10.1037/1076-8998.10.3.187

Gorsuch, R. L. (1983). Factor Analysis, 2nd Edn. Hillsdale, NJ: Lawrence Erlbaum Associates.

Hair, J. F., Ringle, C. M., and Sarastedt, M. (2011). PLS-SEM: indeed a silver bullet. J. Market. Theor. Pract. 19, 139-151. doi: 10.2753/MTP1069-6679190202

Halbesleben, J. R. B., and Wheeler, A. R. (2008). The relative roles of engagement and embeddedness in predicting job performance and intention to leave. Work Stress Int. J. Work Health Organ. 22, 242-256. doi: 10.1080/02678370802383962

Hill, T., and Lewicki, P. (2006). Statistics: Methods and Applications. Tulsa, OK: StatSoft.

Hsu, I.-C. (2008). Knowledge sharing practices as a facilitating factor for improving organizational performance through human capital: a preliminary test. Expert Syst. Appl. 35, 1316-1326. doi: 10.1016/j.eswa.2007.08.012

Janssen, O., and Van Yperen, N. W. (2004). Employees' goal orientations, the quality of leader-member exchange and the outcomes of job performance and job satisfaction. Acad. Manag. J. 47, 368-384. doi: 10.2307/20159587

Kim, J. O., and Mueller, C. W. (1978). Introduction to Factor Analysis: What It is and How to Do It. Beverly Hills, CA: Sage.

Kline, P. (2002). An Easy Guide to Factor Analysis. London: Routledge.

Kuncel, N. R., Hezlett, S. A., and One's, D. S. (2004). Academic performance, career potential, creativity, and job performance: can one construct predict them all? J. Pers. Soc. Psychol. 86, 148-161. doi: 10.1037/0022-3514.86.1.148

Lennick, D., and Kiel, F. (2007). Moral Intelligence: Enhancing Business Performance and Leadership Success. Upper Saddle River, NJ: Wharton School Publishing.

Locke, E. A., and Latham, G. P. (2002). Building a practically useful theory of goal setting and task motivation: a 35-year odyssey. Am. Psychol. 57, 705-717. doi: 10.1037/0003-066X.57.9.705

Markos, S., and Sridevi, M. S. (2010). Employee engagement: the key to improving performance. Int. J. Bus. Manag. 5, 89-96. doi: 10.5539/ijbm.v5n12p89

Martinuzzi, B. (2009). The Leader as a Mensch: Become the Kind of Person Others Want to Follow. San Francisco, CA: Six Seconds Emotional Intelligence Press.

Matteson, M. T., and Ivancevich, J. M. (1987). Controlling Work Stress: Effective Human Resource and Management Strategies. San Francisco, CA: Jossey-Bass.

Meerding, W. J., Ijzelenberg, W., Koopmanschap, M. A., Severens, J. L., and Burdorf, A. (2005). Health problems lead to considerable productivity loss at work among workers with high physical load jobs. J. Clin. Epidemiol. 58, 517-523. doi: 10.1016/j.jclinepi.2004.06.016

Mento, A. J., Steel, R. P., and Karren, R. J. (1987). A meta-analytic study of the effects of goal setting on task performance: 1966-1984. Organ. Behav. Hum. Decis. Process. 39, 52-83. doi: 10.1016/0749-5978(87)90045-8 
Morgeson, F. P., Campion, M. A., Dipboye, R. L., Hollenbeck, J. R., Murphy, K., and Schmitt, N. (2007). Reconsidering the use of personality tests in personnel selection contexts. Pers. Psychol. 60, 683-729. doi: 10.1111/j.1744-6570.2007.00089.x

Motowidlo, S. J., Packard, J. S., and Manning, M. R. (1986). Occupational stress: its causes and consequences for job performance. J. Appl. Psychol. 71, 618-629. doi: 10.1037/0021-9010.71.4.618

Pearson, C. A. L. (1987). Participative goal setting as a strategy for improving performance and job satisfaction: a longitudinal evaluation with railway track maintenance gangs. Hum. Relat. 40, 473-488. doi: $10.1177 / 001872678704000801$

Pronk, N. P., and Kottke, T. E. (2009). Physical activity promotion as a strategic corporate priority to improve worker health and business performance. Prev. Med. 49, 316-321. doi: 10.1016/j.ypmed.2009.06.025

Rich, B. L., Lepine, J. A., and Crawford, E. R. (2010). Job engagement: antecedents and effects on job performance. Acad. Manag. J. 53, 617-635. doi: 10.5465/AMJ.2010.51468988

Schwepker, C. H., and Ingram, T. N. (1996). Improving sales performance through ethics: the relationship between salesperson moral judgment and job performance. J. Bus. Ethics 15, 1151-1160. doi: 10.1007/BF00412814

Spearman, C. (1950). Human Ability. London: Macmillan. [This book was published posthumously.]

Sullivan, S. E., and Bhagat, R. S. (1992). Organizational stress, job satisfaction and job performance: where do we go from here? J. Manage. 18, 353-374.

Tabachnick, B. G., and Fidell, L. S. (2001). Using Multivariate Statistics, 4th Edn. Needham Heights, MA: Allyn and Bacon.
Trochim, W. M., and Donnelly, J. P. (2014). Estimates of Statistics for the Behavioral Sciences, 8th Edn. Belmont, CA: Wadsworth.

Van Scotter, J. R., and Motowidlo, S. J. (1996). Interpersonal facilitation and job dedication as separate facets of contextual performance. J. Appl. Psychol. 81, 525-531. doi: 10.1037/0021-9010.81.5.525

Vogt, W. P. (1993). Dictionary of Statistics and Methodology: A Nontechnical Guide for the Social Sciences. Newbury Park, CA: Sage.

Weitz, B. A., Sujan, H., and Sujan, M. (1986). Knowledge, motivation, and adaptive behavior: a framework for improving selling effectiveness. J. Mark. 50, 174-191. doi: $10.2307 / 1251294$

Worthigton, R. L., and Whittaker, T. A. (2006). Scale development research: a content analysis and recommendations for best practices. Couns. Psychol. 34, 806-838. doi: 10.1177/0011000006288127

Yaremko, R. M., Harari, H., Harrison, R. C., and Lynn, E. (1986). Handbook of Research and Quantitative Methods in Psychology: For Students and Professionals. Hillsdale, NJ: Lawrence Erlbaum Associates.

Conflict of Interest Statement: RB-O is the founder of Bar-On Test Developers LLC and currently directs the R\&D at Bar-On Test Developers.

Copyright $\odot 2018$ Bar-On. This is an open-access article distributed under the terms of the Creative Commons Attribution License (CC BY). The use, distribution or reproduction in other forums is permitted, provided the original author(s) and the copyright owner are credited and that the original publication in this journal is cited, in accordance with accepted academic practice. No use, distribution or reproduction is permitted which does not comply with these terms. 


\section{APPENDIX}

Appendix A | The eight categories listed below describe what pre-employment tests, in the 20th edition of the Mental Measurement Yearbook, appear to evaluate based on a random sample of 120 of the 359 tests that were examined.
1. Vocational \& career interests [11 (9.2\%)]
2. Employability \& general / specific employment skills needed in various occupations [24 (20.0\%)]
3. Cognitive intelligence \& academic ability / skills / readiness / achievement [44 (36.7\%)]
4. Intra-personal competencies \& personality traits [17 (14.2\%)]
5. Inter-personal compatibility \& communication skills [6 (5.0\%)]
6. Managerial \& leadership skills [4 (3.3\%)]
7. Responsibility / commitment / ethics / integrity / honesty / dependability [10 (8.3\%)]
8. Potential for disruptive psychological problems and/or criminal behavior [4 (3.3\%)]

The number of tests found in each category are included in brackets following each of the eight categories.

Appendix B | A comparison of the $26 \mathrm{MMP}^{\mathrm{TM}}$ scales below with those retained in the MMP3 ${ }^{\mathrm{TM}}$ [in brackets] indicates that $85 \%$ of the original scales were retained based on conducting nine sets Exploratory Factor Analysis.
1. Physical Fitness [retained in the MMP3 ${ }^{\mathrm{TM}}$ ]
2. Discomfort Tolerance [retained in the MMP3 ${ }^{\mathrm{TM}}$ ]
3. General Cognitive Competence [retained in the $\mathrm{MMP}^{\mathrm{TM}}$ ]
4. Situational Awareness [retained in the MMP3 ${ }^{\mathrm{TM}}$ ]
5. Applying Experience [retained in the MMP3 ${ }^{\mathrm{TM}}$ ]
6. Flexibility [retained in the $\mathrm{MMP}^{\mathrm{TM}}$ ]
7. Resourcefulness [retained in the MMP3 ${ }^{\mathrm{TM}}$ ]
8. Decision-Making [retained in the MMP3 ${ }^{\mathrm{TM}}$ ]
9. Action-Planning
10. Rapid Implementation
11. Self-Awareness
12. Self-Control [retained in the $\mathrm{MMP}^{\mathrm{TM}}$ ]
13. General Coping Ability [retained in the $M M P 3^{\mathrm{TM}}$ ]
14. Self-Reliance [retained in the $M M P 3^{T M}$ ]
15. Decisiveness [retained in the MMP3 ${ }^{T M}$ ]
16. Courage [retained in the $\mathrm{MMP}^{\mathrm{TM}}$ ]
17. Meaningfulness [retained in the MMP3 ${ }^{\mathrm{TM}}$ ]
18. Self-Motivation [retained in the MMP3 ${ }^{\mathrm{TM}}$ ]
19. Engagement [retained in the MMP3 ${ }^{\mathrm{TM}}$ ]
20. Determination [retained in the $M M P 3^{T M}$ ]
21. Perseverance [retained in the $\mathrm{MMP}^{\mathrm{TM}}$ ]
22. Humility
23. Social-Awareness [retained in the $M M P 3^{\mathrm{TM}}$ ]
24. Social Responsibility [retained in the $M M P 3^{\mathrm{TM}}$ ]
25. Connectedness [retained in the $M M P 3^{\mathrm{TM}}$ ]
26. Well-Being [partly retained in the MMP3 ${ }^{\mathrm{TM}}$ ] 